Studia de Cultura 12(3) 2020

ISSN 2083-7275

DOI 10.24917/20837275.12.3.1

ROZPRAWY I STUDIA

Dominika Kasprowicz

Uniwersytet Jagielloński

ORCID 0000-0001-7421-2952

Karina Veltzé

Uniwersytet Jagielloński

ORCID 0000-0002-5580-5290

\title{
Badania nad memami internetowymi w świetle wiedzy o nowych mediach - wyzwania metodologiczne
}

\section{Wprowadzenie}

Artykuł porusza problematykę badań nad współczesnymi wytworami internetowymi, jakimi są memy. Perspektywa metodologiczna jawi się jako aspekt szczególnie istotny, z uwagi na nie tylko złożoność formy wyrazu, jaką jest mem, ale także na jego sporą popularność wśród użytkowników mediów elektronicznych. Badacz przystępujący zatem do analizy tego typu grafik musi wziąć pod uwagę nie tylko dotychczasowy stan wiedzy na temat nowych mediów, lecz również zastosować metody i narzędzia, które umożliwią naukowy wgląd w tę, względnie nową, internetową formę satyryczną.

Prezentowane poniżej rozważania, oprócz wprowadzenia terminologii oraz charakterystyki środowiska czy użytkowników, skupiają się na spojrzeniu na memy z perspektywy ugruntowanych wyznaczników gatunku medialnego. W niniejszym artykule podjęto próbę odnalezienia wspólnych dla wszystkich memów cech, które mogłyby stanowić o istnieniu nowego gatunku.

Na podstawie tych rozważań, a także wcześniejszych analiz, zaprezentowane zostały propozycje o naturze metodologicznej. Posiłkując się refleksjami innych badaczy, ale przede wszystkim własną obserwacją i badaniami, postawiona została propozycja podejścia do analizy tego typu materiałów wizualnych. Ona zaś może pełnić funkcję wstępu do tego wycinka internetowego świata w celu dalszej i dokładniejszej eksploracji nie tylko samych memów, ale też społeczności tworzącej się wokół nich.

\section{Czym są memy internetowe?}

Punkt wyjścia do definicji memu internetowego stanowi postulat Wiktora Kołowieckiego, aby mem rozpatrywać jako zdigitalizowaną jednostkę informacji, rozpowszechnioną $w$ internecie, skopiowaną, przetworzoną i opublikowaną $w$ tej formie (Kołowiecki 2012). Badacz ten jednak skupia się przede wszystkim na memie jako nośniku informacji, odsuwając jego potencjał przenoszenia i utrwalania idei 
na dalszy plan. Dlatego warto poszerzyć nieco wyjaśnienie tego terminu o propozycję Krzysztofa Piskorza, który szczególny akcent kładzie na ideę właśnie (Piskorz 2015: 651). Zauważmy jednak, że memy zarówno stanowią nośnik, jak i są ideami samymi w sobie. Warto dostrzec w tym momencie potencjał, jaki ze sobą niosą: semantyczny, satyryczny, opiniotwórczy, a nawet informacyjny. Istotnym aspektem pozostaje zatem nie tyle forma dystrybucji owych pomysłów, ile cel ich tworzenia, ponieważ to wśród nich występuje zdecydowane zróżnicowanie. Forma, jak zostanie to w kolejnej części artykułu nakreślone, pozostaje czytelna, w miarę spójna i łatwa w identyfikacji.

Innych, dużo bardziej skrótowych definicji memów nie brakuje, a naukowcy starają się jak najlepiej oddać ich istotę w atrakcyjnej (jak same memy) formie. Wśród proponowanych wyjaśnień terminu znajdują się między innymi: artefakty kultury popularnej (Brylska, Gackowski 2017), nowe formy komunikacyjno-gatunkowe (Gumkowska 2015), montaż z dostępnych klocków kulturowych (Nowak 2013: 240), szczególne pomysły przedstawione w formie tekstu pisanego, obrazu lub ruchu językowego (Shifman 2013) czy praktyczne zastosowanie oszczędności poznawczej w przesyconym informacją świecie (Polański 2013).

Wśród cech charakterystycznych tych wirtualnych wytworów zdecydowanie dominuje anonimowość twórcy, którego tożsamość, mimo dodawania swojego pomysłu wyłącznie za pomocą specjalnie utworzonego konta, nadal pozostaje tajemnicą. Stawia to oczywiście pod znakiem zapytania jego wiarygodność wśród specyficznej społeczności, jaką są inni twórcy i konsumenci memów. Istnieje bowiem wysokie ryzyko, że za rozprzestrzenianiem niektórych idei stoją zawodowcy $\mathrm{z}$ agencji marketingowych.

Anonimowość, a także wirusowy sposób rozprzestrzeniania się memów sprzyja brakowi poszanowania praw autorskich oraz przekraczaniu tabu, łamaniu zasad moralnych, estetycznych czy językowych. Wirusowe rozprzestrzenianie, czyli dyfuzja informacji, która odbywa się za pośrednictwem kolejnych jej odbiorców, przekazujących ją „dalej”, jest istotną cechą. Oczekiwania i przyzwyczajenia odbiorców wymuszają z kolei, aby ten, kto chce podzielić się ze światem swoimi przemyśleniami w formie memu, zrobił to w maksymalnie skondensowany sposób przy użyciu naturalnych dla tego środowiska środków wyrazu, na przykład gry językowej, szyderstwa, analogii, zaawansowanej symboliki, dowcipnej puenty, amplifikacji, ironii czy dialogu z tekstami popkultury. Dla większości memów znamienna jest również poetyka kolażu, przechodząca bardzo często w kicz. Co ważne, wszelkie przejawy nieprofesjonalizmu, elementy cyberjęzykowe, wulgaryzmy czy inne odstępstwa od przyjętych norm to przejaw wiarygodności danego przekazu (Kamińska 2017).

Nie bez znaczenia pozostaje także przestrzeń będąca kuźnią memów internetowych, gdzie następuje wstępna selekcja zamieszczanych przez użytkowników treści. Selekcja ta ma charakter dwustopniowy - najpierw udostępniony materiał musi zaakceptować nota bene anonimowy administrator strony (tak zwany admin), a później użytkownicy, za pomocą systemu przydzielania „plusów” i „minusów”, oceniają każdego mema i w ten sposób decydują czy z „poczekalni”, czyli podstrony, trafi on na stronę główną, będącą najbardziej pożądanym dla twórców miejscem ekspozycji. Strony udostępniające przestrzeń do publikowania swoich rozważań i przemyśleń 
w tej konkretnej graficznej formie to imageboardy, które można przetłumaczyć jako fora obrazkowe. Choć należy zaznaczyć, że dosłowny przekład brzmi „tablice z obrazkami", jednak tego typu terminologia nie funkcjonuje w polskiej literaturze.

Termin forum obrazkowe, choć w ujęciu ogólnym ukazuje specyfikę omawianych stron, nie oddaje w pełni ich funkcji i możliwości. W artykułach innych badaczy zajmujących się tą tematyką można odnaleźć inne ciekawe propozycje polskiego odpowiednika słowa imageboard, lecz żadne z nich nie jest kompletne ani wyczerpujące: portal rozrywkowy, serwis rozrywkowy, strona agregator treści, strona próżności czy nawet śmietnik sieci. Spośród nich forum obrazkowe wydaje się najbardziej adekwatnym, ponieważ leksem forum wyjaśnia, do czego służy tego typu strona (wymiana myśli, dyskusja, komentarz), obrazkowe zaś wskazuje na dominujący tam środek wyrazu. Same memy, jak również agregujące je portale internetowe stanowią odpowiedź na zapotrzebowanie ze strony użytkowników. Z jednej strony potrzeby te napędza postęp technologiczny, z drugiej cechy charakteru oraz stylu bycia i stosunku do świata konsumentów, których zdecydowana większość to osoby młode. Ich młodość jednak nie powinna być kategoryzowana z perspektywy biologicznej, a raczej społeczno-kulturowej czy społeczno-historycznej (Marzęcki 2011: 11). Zwyczaje w poruszaniu się po świecie wirtualnym wśród takich osób określają cechy pokolenia klik, dla którego naturalnym jest uzewnętrznianie swoich myśli i poglądów w sieci, posługiwanie się sloganami, skrótami i linkami, a także płynna obsługa urządzeń elektronicznych czy łatwość przystosowywania się do zmian.

\section{Mem jako odrębny gatunek medialny?}

Internetowe memy stanowią swoistą soczewkę społecznych nastrojów. W świadomości przeciętnego odbiorcy funkcjonują jako syntetyczny, najczęściej dowcipny komentarz dotyczący życia społecznego, politycznego czy emocjonalnego, opakowany w bezpieczną i znaną formę statycznej lub ruchomej grafiki. Te cieszące się największą popularnością z reguły ograniczają się do rozmiarów ekranu komputera lub smartfona bez potrzeby przewijania w celu obejrzenia całości. Choć same memy, jak i ich kanały dystrybucji, czyli fora obrazkowe, nie pozostają całkowicie niezależne od mediów tradycyjnych (w końcu z nich czerpią część eksploatowanych tematów), to zdecydowanie wykazują w pewnym stopniu cechy medium. Powtarzając za Darią Krzewniak, są to: poruszanie kwestii o dużej wadze społecznej, nagłaśnianie i powszechna dyskusja nad ważnymi problemami, fragmentaryczny charakter obserwacji, eksploracja tematów interesujących, zaskakujących bądź przerażających dla potencjalnego odbiorcy (Krzewniak 2015: 151).

Poza wykazywaniem najważniejszych cech odrębnego medium memy pod pewnymi względami spełniają wyznaczniki gatunku medialnego, który - przywołując za Zbigniewem Bauerem - stanowi zespół jednorodnych, czytelnych norm kodowania i dekodowania wypowiedzi w prasie, radiu i telewizji, opublikowanych dzięki medium (Bauer 2012: 257). Problem jednak leży w tym, że mem nie posiada formalnie sklasyfikowanych cech, jakie powinien mieć, aby za mema zostać uznanym. Twórcy kierują się zatem niepisanymi zasadami, jak grafika powinna wyglądać, a jej treść uzależniają od aktualnych zapotrzebowań odbiorców i trendów w sieci. 
Korzeni memów należy upatrywać w dobrze znanych i ugruntowanych w świadomości medioznawców gatunkach medialnych publicystyki wizualnej, takich jak karykatura czy rysunek satyryczny. Autorzy z forów obrazkowych posługują się bowiem przejaskrawieniami, prawem kontrastu czy stylistyką paszkwilu równie zręcznie jak profesjonalni rysownicy prasowi (Kozieł 2013: 37). Niektórzy badacze uznają wręcz, że memy to nowa, wyewoluowana i dostosowana do współczesności oraz sposobu życia odbiorcy forma satyry (Juza 2014: 241).

Patrząc na gatunki medialne szerzej, nie sposób nie podjąć próby doszukiwania się podziału memów na klasyczną informację oraz publicystykę. Jako że te amatorskie grafiki głównie komentują i obśmiewają, oczywistym będzie, że reprezentują szeroko pojętą publicystykę, bardziej lub mniej profesjonalnie dokonaną. Część memów wykazuje jednak cechy gatunków informacyjnych, a są to przede wszystkim wkomponowane w ramę memową zrzuty ekranów z newsami czy po prostu obrazy z samym czysto informacyjnym tekstem pozostawione bez komentarza, który mógłby wskazywać drogę interpretacji. Do tego rodzaju działań zaliczają się również infografiki, stanowiące jednak znikomy procent propozycji internautów ${ }^{1}$.

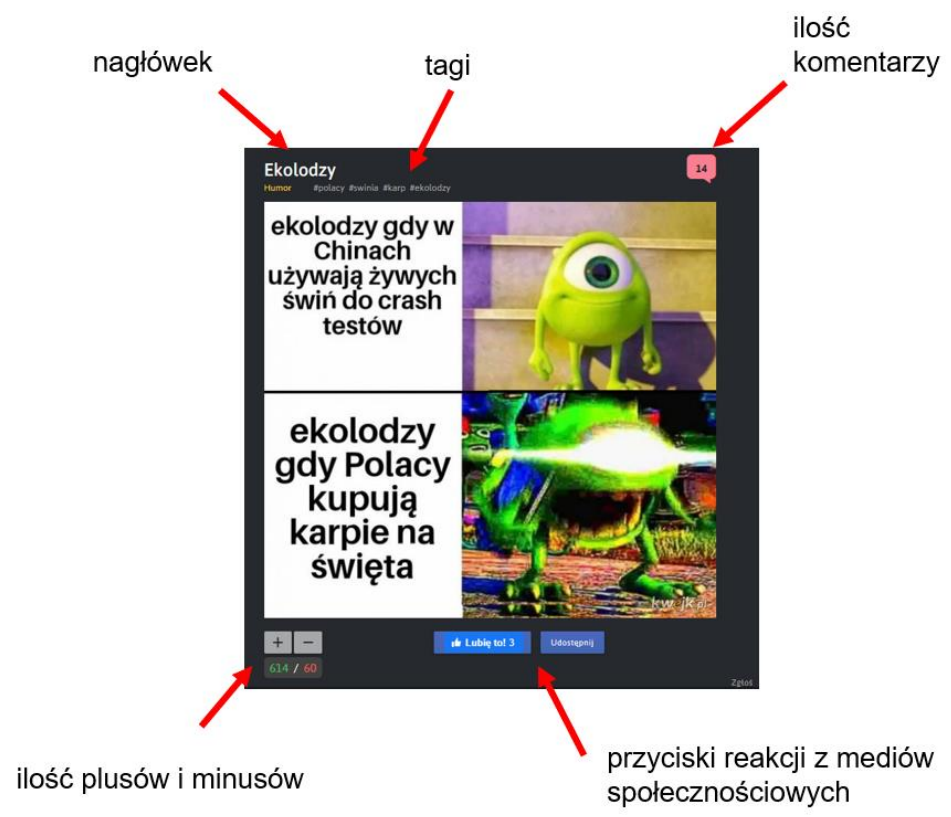

II. 1. Układ ramy kompozycyjnej memu internetowego. Źródło: opracowanie własne; grafika https://kwejk.pl/obrazek/3473053/ekolodzy.html (dostęp: 4.01.2020)

${ }^{1}$ Wiedza o tego typu proporcjach bazuje na wynikach badań jednej z autorek, przeprowadzonych na potrzeby pracy dyplomowej „Forum obrazkowe jako przestrzeń komunikacji politycznej w Polsce". Wyniki dotyczą zawartości reprezentatywnej próby memów politycznych, aczkolwiek można dane te odnieść do ogółu. 
Każdy gatunek medialny posiada pewne cechy wyróżniające go spośród innych form, co pozwala na szybką identyfikację i klasyfikację. Nie inaczej jest z memami internetowymi, choć niektóre z ich cech nie wydają się od razu takie oczywiste. Z pewnością memy posiadają własne medium rozpowszechniające, o którym była szerzej mowa powyżej - fora obrazkowe. Mimo że grafiki te można spotkać w różnych meandrach sieci, większość z nich swój początek bierze właśnie na forach obrazkowych, które umożliwiają udostępnienie swoich materiałów w sposób szybki i usystematyzowany, a zarazem od razu trafiający do szerokiego grona odbiorców bez odautorskiej ingerencji w promocję.

Kompozycja i układ to także wyznaczniki, które mogłyby pozwolić na rozpatrywanie memu w kontekście odrębnego gatunku medialnego. Każdy mem, czy to rozbudowany (np. komiks, kolaż, fotoopowieść) czy nie (np. obrazek, gif), wpisany jest w pewną ramę kompozycyjną, którą narzuca regulamin stron agregatorów, ale na ten moment także przyzwyczajenia i oczekiwania odbiorców. Na ramę tę składają się poszczególne elementy: nagłówek, treść, sekcja ocen, sekcja komentarzy, tagi, kategoria oraz przyciski odsyłające do kont w mediach społecznościowych. Niektóre fora udostępniają również informację o orientacyjnej dacie dodania.

Styl to element, który jest bardzo charakterystyczny dla memów internetowych. Zaawansowane elementy cyberjęzykowe nie tylko uwiarygadniają przekaz wśród „memowych” społeczności, ale także stanowią odpowiedź na językowe zwyczaje czy oczekiwania użytkowników. Im większe nagromadzenie błędów, slangów, wyrażeń wulgarnych czy skrótów używanych przede wszystkim w wirtualnym świecie, tym popularność grafiki wzrasta, dając szanse na zakorzenienie się w umysłach forumowiczów.

Szczegółowość i zwięzłość to cecha memu, która wymaga głębszego zastanowienia, a także dokładnego zbadania. Z jednej strony forma przekazu sama w sobie jak najbardziej nosi znamiona skondensowania, w ograniczonej bowiem ramie należy przedstawić swoje refleksje tak, aby ich konsumpcja nie wymagała od odbiorcy większego niż to konieczne zaangażowania. Z drugiej strony dla pozostających poza internetowymi, a już w szczególności memowymi trendami nie każdy mem musi być na tyle szczegółowy, aby mógł być zrozumiały bez znajomości kontekstu. Często poszczególne grafiki to kontynuacja cyklu, kolejna matryca lub po prostu celowe wprowadzanie w błąd (np. trolling), będące tylko wycinkami toku myślenia autora, a umiejętność ich rozszyfrowania posiadają wyłącznie stali bywalcy danego forum. $\mathrm{Na}$ aspekt ten zwrócili już uwagę badacze, wskazując, że wokół memów tworzy się wspólnota „wiedzących, o co chodzi” (Piskorz 2015: 227), pozostawiając innych w wykluczeniu, a nawet w zagrożeniu informacyjnym.

Pod znakiem zapytania można postawić kwestię relacji autor - odbiorcy. O ile cel przyświecający twórcom, czyli chęć podzielenia się swoimi przemyśleniami, dowcipem, skomentowania otaczającej rzeczywistości, pozostaje jasny, o tyle niejasna jest jego pozycja względem odbiorców. Dzięki sekcji komentarzy i ocen mają oni nie tylko dostęp do bezpośredniej, często surowej oceny, ale też do otwartego ataku na autora i w konsekwencji pozbawienia go roli kreatora opinii. Jeśli chodzi o memy matryce, twórcy stawiają się z góry na pozycji odtwórczej eksploatacji, gdzie kreatywność ogranicza się do podmiany jednego elementu w utartych schematach. 
Warto przy tym pamiętać, że autorzy, mimo posiadania konta, pozostają anonimowi dla ogółu społeczności.

Ostatnim omawianym wyznacznikiem gatunku medialnego będzie cel i funkcja publikacji. Z uwagi na definicję forum obrazkowego podstawowa funkcja ogranicza się do zapewnienia użytkownikom rozrywki. Humor, będący elementem dominującym, pełni jednak o wiele istotniejszą funkcję niż zwykłe zrelaksowanie i zapewnienie odskoczni od trudów dnia codziennego. Ma on za zadanie oswajać tematy trudne, niewygodne, kontrowersyjne, podawać w wątpliwość reguły życia społecznego, integrować, prowokować, a także niepokoić. Należy bowiem zważyć, że memy to nie są klasyczne kawały, lecz aktualne i ponadczasowe problemy z przeróżnych sfer życia ludzkiego, otoczone aurą dowcipu, ukazane za pomocą zabawnej analogii, poddane w zabawnej formie pod dyskusję czy indywidualne refleksje. Wbrew powszechnemu przekonaniu o swej trywialności memy poruszają głębokie kwestie natury społecznej, kulturowej, politycznej, emocjonalnej czy wreszcie moralnej.

\section{Jak badać memy internetowe?}

Memy internetowe to w swej prostocie jednostki badawcze cechujące się sporym skomplikowaniem. Niedogodność leży przede wszystkim w dużej ilości elementów składowych, które można zliczyć czy odnotować (zob. il. 1), przy jednoczesnym zaawansowaniu przedstawień symbolicznych oraz użytych zabiegów wizualnych i językowych w samej treści tego typu grafiki. Badacz staje zatem wobec wielowarstwowej, wieloznacznej treści zamkniętej w niewielkim przekazie wizualnym, gdzie każda z warstw może nanosić inne znaczenie, a także odwracać znaczenie pozostałych. Przykładem tego jest obecność nagłówka, który w wielu wypadkach zmienia sposób odczytywania memu o 180 stopni. Niezbędnym punktem wyjścia przy tego typu badaniach jest w miarę swobodne poruszanie się naukowca w wirtualnym środowisku, wyczuwanie i rozumienie internetowych trendów, a także niezwykła wrażliwość na wszelką żonglerkę reprezentacjami symbolicznymi, aluzjami do tekstów kultury (wysokiej oraz masowej) tudzież środkami stylistycznymi i językowymi.

Proponowana metodologia zakłada podzielenie badań na dwa etapy, gdzie pierwszy stanowi ujęcie ilościowe, drugi jakościowe. Tego typu mieszany schemat badawczy zakłada jak najlepsze uchwycenie specyfiki badanego materiału, a co za tym idzie - dogłębną eksplorację wizualnych materiałów typu memy (Kasprowicz 2013: 479-499). W zależności zaś od tego, na co badacz chce kłaść nacisk, może poprzestać wyłącznie na jednej z zaproponowanych ścieżek.

Ilościowa analiza zawartości zakłada bardziej podejście do memu jako gatunku medialnego. Narzędziem, które temu służy, jest klucz kategoryzacyjny. Pomaga on zakodować każdą jednostkę (jednostka to pojedynczy mem ubrany w ramę kompozycyjną) pod względem kompleksowym lub aspektowym. Klucz ma na celu nie tylko odczyt danych, takich jak na przykład liczba plusów, komentarzy czy tagów, ale również indywidualne określenie formy graficznej, poprawności dopasowania do kategorii, obecność ironii, wulgaryzmów. Szczegółowo zaprojektowany klucz pomoże także znaleźć odpowiedzi na pytania: kto znajduje się na memie, do jakiego wydarzenia lub sytuacji nastąpiło odwołanie, jaka wybrzmiewa z niego postawa. 
W takim narzędziu można postawić pytanie stricte nastawione na pozyskanie informacji o memie jako gatunku, „prześwietlając” każdą jednostkę pod kątem na przykład elementów cyberjęzykowych. Z tak przeprowadzonej analizy ilościowej można otrzymać twarde dane liczbowe do zestawień i porównań, przy założeniu, że do badań zaklasyfikowano reprezentatywną próbę.

Ścieżka jakościowa obiera za metodę analizę semiotyczną, której narzędziem jest schemat tejże analizy. Schemat stanowi z kolei esencję podejść różnych badaczy, a sposób jego skonstruowania ma na celu jak najlepiej wyeksponować zamysł autora, odczytać oraz zdemaskować ukryte intencje i ostateczny sens. Oprócz podstawowych zabiegów, takich jak odczytanie porządku komponentów, określenie planów, kolorów czy zastosowania przeróbek graficznych, należy uwzględnić szersze spojrzenie. Klasyczne i utrwalone w badaniach nad wizualnością propozycje muszą zatem zostać wzbogacone o świeże idee wysunięte przez współczesnych specjalistów w dziedzinie badań nad memami.

Podstawowym założeniem schematu analizy semiotycznej musi być rozkład materiału graficznego na warstwę denotatywną (to, co widać na memie) i konotatywną (to, jakie skojarzenia przywołują elementy). Idąc dalej, za propozycją Karoliny Brylskiej i Tomasza Gackowskiego, warto rozbudować to podejście o dekonstrukcję syntagmy znaczeniowej (obrazu i słowa), a następnie rekonfigurację znaczeń obu warstw (Brylska, Gackowski 2017: 32). Powstały w ten sposób materiał posłuży do interpretacji semiologicznej, co w praktyce sprowadza się do nadania znaczeń kulturowych postawionych w memach znakom.

Połączenie wyżej wymienionych sugestii warto uzupełnić o szablon, który zaproponowała badaczka Limor Shifman. Według jej zamysłu, analiza memu powinna odbywać się w trzech wymiarach: zawartości, formy, postawy, przy założeniu, że badaniom podlega klasyczny mem matryca (Shifman 2014). To właśnie wymiana jednego z kompozytów sprawia, że memy zmieniają swój wydźwięk.

Dzięki rozłożeniu na warstwy znaczeniowe, a nie badaniu jednostki analizy jako jednolite byty, memy stają się dla naukowca bardziej zrozumiałe, łatwiej mu zaobserwować niepisane zasady rządzące „memową” społecznościową, a w szczególności twórcami, oraz prawidłowo odebrać płynący zeń przekaz. W świetle tego, że memy odznaczają się wysokim potencjałem opiniotwórczym, ich poprawne dekodowanie i dogłębne poznanie nabiera jeszcze większego znaczenia. Połączenie zaproponowanych wyżej metod badawczych powinno przybliżyć do dokładnej eksploracji tego niezwykłego środowiska oraz stanowić wstęp do badań nad społecznością forum czy innymi możliwościami wykorzystania drzemiącego w memach potencjału.

\section{Podsumowanie}

Badania nad memami wydają się niezwykle interesujące z perspektywy medioznawczej. Mimo że są obecne już dobrych kilka lat w przestrzeni medialnej i społecznej, nie poświęcono im dotychczas dostatecznej ilości czasu w dziedzinie polskich badań medioznawczych. Dotychczasowa literatura skupia się raczej na 
teoretycznym ujęciu genezy memów, ich funkcji i znaczenia społecznego, jednak niewielu badaczy podejmuje się dogłębnego, empirycznego zbadania tego fenomenu.

Wartym odnotowania pozostaje fakt, że obszarem równie ciekawym jak memy pozostaje ich „naturalne środowisko”, czyli fora obrazkowe. Jeszcze innym nurtującym zagadnieniem pozostaje społeczność, która się wokół owych forów skupia - jej zwyczaje, sposób użytkowania mediów czy wreszcie rodzaj i charakterystyka więzi między nimi. Wszystkie te składowe dają całość obrazu funkcjonowania pewnego wycinka środowiska internautów, o których wiedza jawi się jako ważna z punktu widzenia badaczy wirtualnej rzeczywistości.

To właśnie w wyżej wymienionych aspektach wciąż pozostaje nie do końca odkryte pole dla badaczy, ponieważ o ile same fora dyskusyjne są dość dobrze omówione w literaturze, o tyle fora, gdzie rządzi obraz, niekoniecznie. Dzięki zaprezentowanemu w artykule, nieco odmiennemu sposobowi postrzegania i badania memów możliwe jest dobre poznanie toku rozumowania twórców, oczekiwań odbiorców, zwyczajów i trendów rządzących tego typu wizualnymi produktami internetu. Drzemiący w nich potencjał pozostaje niewątpliwie istotny, a moc ich oddziaływania daje się odczuć w codziennym użytkowaniu mediów, co z kolei skłania do pochylenia się nad problemem i kontynuacji badań w tymże kierunku.

\section{Bibliografia}

Bauer Zbigniew. 2012. Gatunki dziennikarskie. W: Dziennikarstwo i świat mediów. Edward Chudziński, Zbigniew Bauer (red.). Kraków. 255-280.

Brylska Karolina, Gackowski Tomasz. 2017. Krytyka polityczna w memach internetowych - od dekonstrukcji po rekonfigurację. W: Memy czyli życie społeczne w czasach kultury obrazu. Karolina Brylska, Tomasz Gackowski, Mateusz Patera (red.). Kraków. 25-49.

Gumkowska Anna. 2015. „Mem - nowa forma komunikacyjno-gatunkowa w sieci”. Teksty Drugie nr 3/2015. 213-235.

Juza Marta. 2014. Wykorzystanie internetowych środków przekazu w procesie komunikowania politycznego. W: Media i polityka. Relacje i współzależności. Małgorzata Adamik-Szysiak (red.). Lublin. 231-248.

Kamińska Magdalena. 2017. Memosfera: wprowadzenie do cyberkulturoznawstwa. Poznań.

Kasprowicz Dominika. 2013. Metody mieszane i ich zastosowanie w badaniach partii politycznych. W: Podejścia badawcze i metodologie w nauce o polityce. Barbara Krauz-Mozer, Paweł Ścigaj (red.). Kraków. 479-499.

Kołowiecki Wiktor. 2012. Memy internetowe jako nowy język internetu. http://www. kulturaihistoria.umcs.lublin.pl/archives/3637. (dostęp: 4.01.2020).

Kozieł Andrzej. 2013. Publicystyka wizualna w prasie: karykatura, rysunek satyryczny, fotomontaż. W: Komunikacja wizualna w prasie i mediach elektronicznych. Kazimierz Wolny-Zmorzyński (red.). Warszawa. 35-44.

Krzewniak Daria. 2015. Media w społeczeństwie informacyjnym. W: Kultura informacyjna w ujęciu interdyscyplinarnym - teoria i praktyka. Hanna Batorowska (red.). Kraków. 146-159.

Marzęcki Radosław. 2011. Młody obywatel we współczesnej demokracji. Warszawa. 
Nowak Jakub. 2013. Memy internetowe: teksty (cyfrowej) kultury językiem krytyki społecznej. W: Współczesne media: język mediów. Iwona Hofman, Dorota Kępa-Figura (red.). Lublin. 227-238.

Piskorz Krzysztof. 2015. „Internet nie śpi, internet reaguje. Memy internetowe jako forma komentarza do bieżących wydarzeń społecznych i politycznych". Zeszyty Prasoznawcze nr 3. 240.

Polański Grzegorz. 2013. Heurystyki wydawania sądów społecznych w mediach. W: Człowiek, media, edukacja. Janusz Morbitzer, Emilia Musiał (red.). Kraków. 326332.

Shifman Limor. 2013. „Memes in a Digital World: Reconcilling with a Conceptual Trouble-maker". Journal of Computer-Mediated Communication nr 3/2013. https://online-library.wiley.com/doi/full/10.1111/jcc4.12013. (dostęp: 4.01.2020).

Shifman Limor. 2014. Memes in digital culture. Cambridge - London.

\title{
Streszczenie
}

Memy interenetowe to zróżnicowane formy wizualne: od obrazka z błyskotliwym podpisem do różnorodnych grafik, ruchomych lub statycznych, często zawierających większe partie tekstu. Mem jako nośnik informacji jest formatem złożonym - wyczerpuje po części definicję gatunku dziennikarskiego. Analiza memów wymaga przemyślanej metodologii. W wypadku tego krótkiego, acz wieloaspektowego minigatunku niezbędne są mieszane metody badawcze. Warto przy tym pamiętać, że mem jako jednostka to nie tylko warstwa wizualna i słowna, ale również wachlarz narzędzi - możliwość oceny oraz skomentowania przez użytkowników.

\section{Research into Internet memes in the light of knowledge about new media - methodological challenges}

\begin{abstract}
Internet memes are differentiated visual forms: ranging from images with witty captions to various mobile or static graphics, which often contain larger fragments of text. A meme as a carrier of information is a complex unit, which partly uses the definition of journalistic writing. The anlaysis of memes requires careful methodology. In the case of this short but multiaspectual mini-genre, mixed research methods are necessary. It is worth remembering that a meme, as a unit, is not only a visual and verbal layer, but also a spectrum of tools, the possibility of assessment and comments by users.
\end{abstract}

Słowa kluczowe: memy, gatunek medialny, analiza semiotyczna, forum obrazkowe

Key words: memes, media genre, semiotic analysis, image forum

Dominika Kasprowicz - dr hab., prof. UJ, pracownik naukowy Instytutu Mediów, Dziennikarstwa i Komunikacji Społecznej w Zakładzie Badań nad Mediatyzacją Uniwersytetu Jagiellońskiego. Jej zainteresowania naukowe to: komunikacja polityczna, populizm i skrajne ruchy prawicowe, strategie komunikacyjne partii politycznych, innowacje polityczne oraz mieszane schematy badawcze.

Karina Veltzé - mgr, absolwentka dziennikarstwa i komunikacji społecznej na Uniwersytecie Jagiellońskim. Obroniła pracę magisterską na temat forów obrazkowych jako alternatywnych środków komunikacji politycznej w Polsce. Jej zainteresowania naukowe to: mariaż polityki z kulturą, komunikacja polityczna w internecie oraz reportaż literacki. 